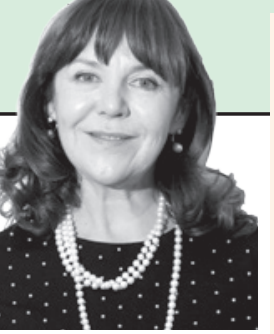

Е. В. ЛЮТЕР

Кандидат экон. наук, доцент кафедрь «Экономика промышленности» ФГБОУ ВО «Московский авиационный институт (Национальныцй исследовательский университет)». Область научных интересов: анализ и диагностика финансово-экономического состояния промышленных предприятий.

\section{E-mail: luter@mai.ru}

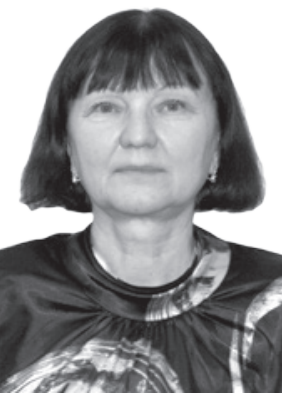

М. М. СТАРКОВА

Кандидат экон. наук, доцент кафедрь «Экономика промышленности» ФГБОУ ВО «Московский

авиационный инсти-

тут (Национальный

исследовательский университет)». Область

научных интересов:

экономико-правовые аспекты антикризисного управления предприятием, методы выбора процедур антикризисного управления.

E-mail:

starkova_maria@mail.ru $\prod$

редложен оригинальный авторский метод оценки финансово-экономической устойчивости предприятий - исполнителей государственного оборонного заказа. Метод учитывает финансовые и экономические показатели деятельности предприятия. Предлагаемый комплексный показатель оценки финансово-экономической устойчивости может быть использован государственным заказчиком на этапе анализа возможностей выполнения государственного контракта потенциальными исполнителями.

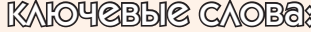

государственный оборонный заказ, государственный контракт, промышленность, заказчик, исполнитель, финансово-экономическая устойчивость, ключевой показатель, оценка финансово-экономической устойчивости, комплексный показатель.

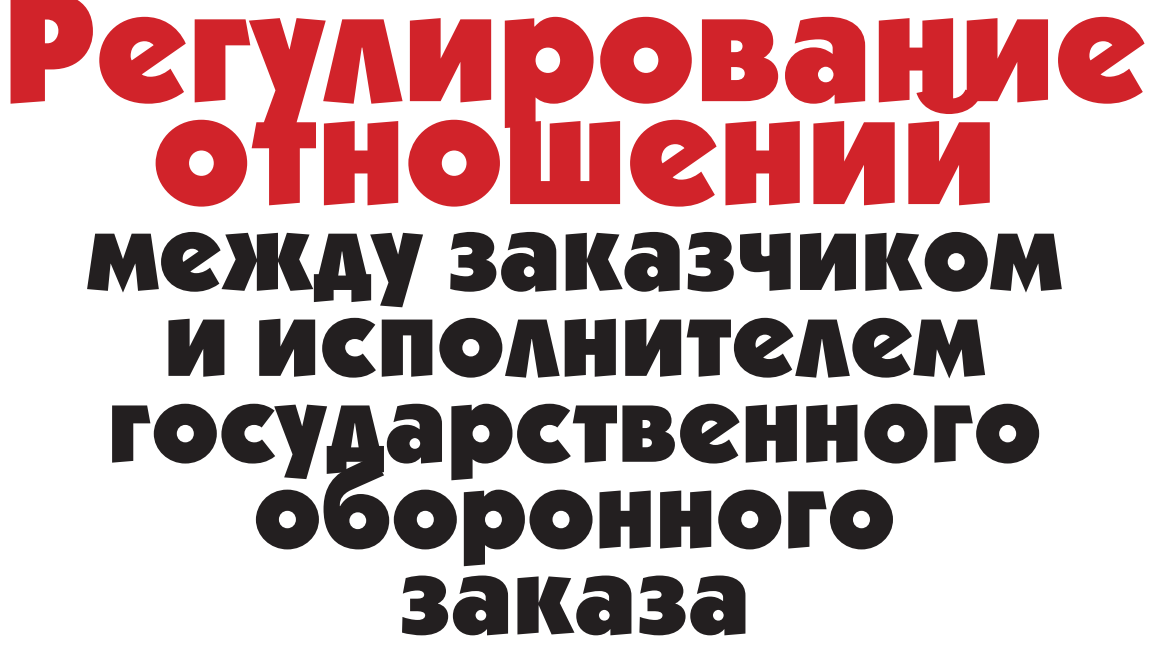

$\Pi$ ри размещении и выполнении государственного оборонного заказа нужна система мер, обеспечивающих контроль за использованием бюджетных средств [Федеральный закон 2012]. Ее ключевым элементом должны стать новые меры регулирования отношений между заказчиком и исполнителем государственного оборонного заказа, включающими методы контроля использования бюджетных средств на основе установления специального банковского сопровождения расчетов между всеми исполнителями контракта, анализа и мониторинга их финансово-экономического состояния, установление взаимодействия исполнителей контрактов, входящих в кооперацию по действующим заказам, заключенным с Министерством обороны РФ. Данный аспект определяет направление расходования бюджетных средств, выполнение го- сударством своих социально-экономических функций и защиту от рисков, связанных с действиями недобросовестных исполнителей (поставщиков, подрядчиков) при заключении и исполнении государственных контрактов.

Президент и председатель правительства Российской Федерации неоднократно указывали на то, что при заключении контрактов складываются коррупционные схемы, сопровождающиеся недоброкачественным выполнением или невыполнением государственного заказа. Предположительный ущерб от нарушений, совершаемых в процессе осуществления закупок для государственных нужд, оценен примерно в 1 трлн руб. [Единая, [б.г.]]. В 2015 году было размещено извещений о закупках на сумму более 6,6 трлн руб. Даже без учета контрактов, сведения о которых составляют государственную

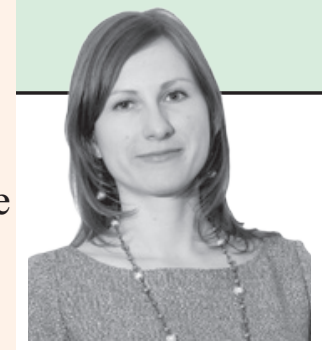

Ю. В. ГУСАРОВА

Кандидат экон. наук, доцент кафедры «Экономика промыиленности" ФГБОУ ВО «Московский авиационный институт (Национальный исследовательский университет)». Область научных интересов: диагностика причин убыточности и оценка эффективности деятельности предприятий промышленности.

E-mail:

gusarova-yulia@rambler.ru

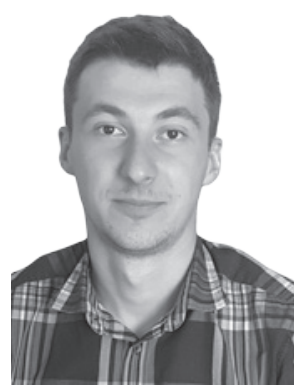

А. С. ВОРОЖЕЙКИН Магистр менеджмента, аспирант кафедры «Экономика промышленности" ФГБОУ ВО «Московский авиационный институт (Национальный исследовательский университет)». Область научных интересов: антикризисное управление, государственный оборонный заказ.

E-mail:

vorojeikin14@mail.ru 
тайну и не размещаются в открытом доступе, общий объем заключенных контрактов составил 5,3 трлн руб. Более 330 тыс. государственных и муниципальных заказчиков и около 500 тыс. поставщиков используют контрактную систему, которая стала одной из крупнейших хозяйственных систем страны. В структуре ВВП страны государственные закупки составляют более $10 \%$ [Единая, [б.г.]]. Вышеприведенная статистика подтверждает необходимость наведения порядка в сфере заключения и выполнения государственных контрактов.

Вступление в силу 5 апреля 2013 года Федерального закона № 44-Ф3 «О контрактной системе в сфере закупок товаров, работ, услуг для обеспечения государственных и муниципальных нужд» не избавило стороны от неустоек за неисполнение или ненадлежащее исполнение поставщиками обязательств в данной сфере. Сведения о подобных санкциях приведены в табл. 1 .

Анализ данных (табл. 1) свидетельствует об увеличении в три раза неустоек за неисполнение или ненадлежащее исполнение поставщиками обязательств в 2015 году, стало больше и поставщиков, которые не соблюдали свои обязательства. Исполнению контрактов с фиксированными ценами препятствовали волатильность рынков, спад в ряде отраслей производства товаров, работ, услуг, нестабильность финансового положения отдельных поставщиков. Недобросовестное исполнение гособоронзаказа подрывает экономическую безопасность страны, снижает обороноспособность и приводит к нестабильности социальной системы.

Одним из средств преодоления такой ситуа- ции могло бы стать комплексное методическое обеспечение взаимодействия между исполнителем и заказчиком в рамках государственного контракта. Прежде всего, необходим анализ финансово-экономического состояния претендентов на выполнение гособоронзаказа и оценка финансово-экономических рисков исполнения контракта. Для этого предлагается метод оценки финансово-экономических рисков при размещении государственного заказа на предприятии. Оценка финансово-экономической устойчивости производится при помощи комплексной оценки ключевых показателей, характеризующих разные стороны деятельности предприятия.

Показатели для оценки финансово-экономических рисков выбираются с учетом экономических интересов заказчика и исполнителя государственного контракта (табл. 2). Их можно разделить на три группы:

- показатели эффективности деятельности предприятия: рентабельность активов, рентабельность продаж, налоговая нагрузка;

- показатели платежеспособности и финансовой устойчивости: коэффициент текущей ликвидности, коэффициент абсолютной ликвидности, степень платежеспособности, коэффициент автономии, коэффициент обеспеченности собственными оборотными средствами;

- показатели экономической устойчивости: среднемесячная выработка на одного работающего, среднемесячная заработная плата одного работающего, фондоотдача.

Метод оценки финансово-экономической устойчивости состоит в переводе действительных значений ключевых показателей оценки финан-
Uрсрективное

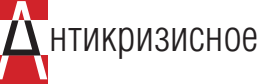

правление

Таблицุа 1

Сведения о начисленных в 2014-2015 г2. за неисполнение или ненадлежацее исполнение поставщиками обязательств неустойках

\begin{tabular}{|c|c|c|c|c|}
\hline \multirow[b]{2}{*}{ Показатель } & \multicolumn{3}{|c|}{ Уровень бюджета заказчика } & \multirow[b]{2}{*}{ Итого } \\
\hline & $\begin{array}{c}\text { Федеральный } \\
\text { уровень }\end{array}$ & $\begin{array}{c}\text { Уровень } \\
\text { субъекта РФ }\end{array}$ & $\begin{array}{c}\text { Муниципальный } \\
\text { уровень }\end{array}$ & \\
\hline $\begin{array}{l}\text { Количество заключенных контрактов, тыс.: } \\
2014 \\
2015\end{array}$ & $\begin{array}{l}690 \\
783\end{array}$ & $\begin{array}{l}1223 \\
1429\end{array}$ & $\begin{array}{c}874 \\
1003\end{array}$ & $\begin{array}{l}2787 \\
3215\end{array}$ \\
\hline $\begin{array}{l}\text { Общий объем заключенных контрактов, млрд руб. } \\
2014 \\
2015 \\
\end{array}$ & $\begin{array}{l}2441 \\
2054\end{array}$ & $\begin{array}{l}2097 \\
2265\end{array}$ & $\begin{array}{l}973 \\
949\end{array}$ & $\begin{array}{l}5511 \\
5268\end{array}$ \\
\hline $\begin{array}{l}\text { Размер начисленной неустойки: } \\
2014 \\
2015\end{array}$ & $\begin{array}{c}557,9 \\
3413,6 \\
\end{array}$ & $\begin{array}{l}2473,1 \\
4694,5 \\
\end{array}$ & $\begin{array}{c}370,0 \\
2987,2 \\
\end{array}$ & $\begin{array}{c}3400,99 \\
11095,74 \\
\end{array}$ \\
\hline $\begin{array}{l}\text { Среднее значение неустойки на } 1 \text { контракт, руб.: } \\
2014 \\
2015\end{array}$ & $\begin{array}{c}809 \\
4273\end{array}$ & $\begin{array}{l}2022 \\
3249\end{array}$ & $\begin{array}{c}424 \\
2928\end{array}$ & $\begin{array}{l}1220 \\
3451\end{array}$ \\
\hline
\end{tabular}


Ключевые показатели, используемые для комплексной оценки финансово-экономической устойчивости исполнителя контракта

\begin{tabular}{|c|c|c|c|}
\hline Показатель & Расчётная формула & Норматив & $\begin{array}{l}\text { Экономическое } \\
\text { содержание }\end{array}$ \\
\hline $\begin{array}{l}\text { Рентабельность } \\
\text { активов }\end{array}$ & $K_{1}=\frac{\text { Прибыль до налогообложения }}{\text { Средняя величина активов }}$ & $\begin{array}{l}\text { Среднее значение } \\
\text { по виду экономической } \\
\text { деятельности }\end{array}$ & $\begin{array}{l}\text { Прибыль, полученная на каж- } \\
\text { дый рубль вложений в активы }\end{array}$ \\
\hline $\begin{array}{l}\text { Рентабельность } \\
\text { продаж }\end{array}$ & $K_{2}=\frac{\text { Прибыль от продаж }}{\text { Выручка от продаж }}$ & $\begin{array}{l}\text { Среднее значение } \\
\text { по виду экономической } \\
\text { деятельности }\end{array}$ & $\begin{array}{l}\text { Оценка эффективности основ- } \\
\text { ной деятельности }\end{array}$ \\
\hline $\begin{array}{l}\text { Налоговая } \\
\text { нагрузка }\end{array}$ & $K_{3}=\frac{\text { Сумма начисленных налогов }}{\text { Выручка от продаж }}$ & $\begin{array}{l}\text { Среднее значение } \\
\text { по виду экономической } \\
\text { деятельности }\end{array}$ & $\begin{array}{l}\text { Оценка налоговых обязательств } \\
\text { предприятия к выручке от про- } \\
\text { даж }\end{array}$ \\
\hline $\begin{array}{l}\text { Коэффициент текущей } \\
\text { ликвидности }\end{array}$ & $K_{4}=\frac{\text { Оборотные активы }}{\text { Краткосрочные обязательства }}$ & $\geq 1,0$ & $\begin{array}{l}\text { Характеризует общую обеспе- } \\
\text { ченность предприятия обо- } \\
\text { ротными средствами, а также } \\
\text { способность расплачиваться } \\
\text { с кредиторами по обязатель- } \\
\text { ствам }\end{array}$ \\
\hline $\begin{array}{l}\text { Коэффициент } \\
\text { абсолютной } \\
\text { ликвидности }\end{array}$ & $K_{5}=\frac{\begin{array}{c}\text { Денежные и приравненные } \\
\text { к ним средства }\end{array}}{\text { Краткосрочные обязательства }}$ & $\geq 0,2$ & $\begin{array}{l}\text { Характеризует способность } \\
\text { предприятия мгновенно рас- } \\
\text { плачиваться по долгам }\end{array}$ \\
\hline $\begin{array}{l}\text { Степень } \\
\text { платежеспособности }\end{array}$ & $K_{6}=\frac{\begin{array}{c}\text { Краткосрочные обязательства } \times \\
\times \text { Период анализа }\end{array}}{\text { Выручка от продаж }}$ & $\leq 3$ мес. & $\begin{array}{l}\text { Оценка возможности пога- } \\
\text { шения обязательств за счет } \\
\text { выручки }\end{array}$ \\
\hline $\begin{array}{l}\text { Коэффициент } \\
\text { автономии }\end{array}$ & $K_{7}=\frac{\text { Собственный капитал }}{\text { Капитал, вложенный в активы }}$ & $\geq 0,5$ & $\begin{array}{l}\text { Характеризует зависимость } \\
\text { от заемных средств }\end{array}$ \\
\hline $\begin{array}{l}\text { Коэффициент } \\
\text { обеспеченности } \\
\text { собственными } \\
\text { оборотными } \\
\text { средствами } \\
\end{array}$ & $K_{8}=\frac{\text { Собственные оборотные средства }}{\text { Оборотные активы }}$ & $\geq 0,1$ & $\begin{array}{l}\text { Характеризует наличие соб- } \\
\text { ственных оборотных средств } \\
\text { предприятия, необходимых } \\
\text { для его финансовой устойчи- } \\
\text { вости }\end{array}$ \\
\hline $\begin{array}{l}\text { Среднемесячная } \\
\text { выработка на одного } \\
\text { работающего, тыс. } \\
\text { руб./чел. }\end{array}$ & $K_{9}=\frac{\text { Выручка от продаж/12 }}{\text { Среднесписочная численность }}$ & $\begin{array}{l}\text { Среднее значение } \\
\text { по виду экономической } \\
\text { деятельности }\end{array}$ & $\begin{array}{l}\text { Оценка эффективности } \\
\text { персонала }\end{array}$ \\
\hline $\begin{array}{l}\text { Среднемесячная } \\
\text { заработная плата } \\
\text { на одного } \\
\text { работающего, } \\
\text { руб./чел. }\end{array}$ & $K_{10}=\frac{\text { Затраты на оплату труда }}{\begin{array}{c}\text { Среднесписочная численность } \\
\text { работников }\end{array}}$ & $\begin{array}{l}\text { Среднее значение } \\
\text { по виду экономической } \\
\text { деятельности }\end{array}$ & Оценка эффективности труда \\
\hline $\begin{array}{l}\text { Фондоотдача, } \\
\text { руб./руб. }\end{array}$ & 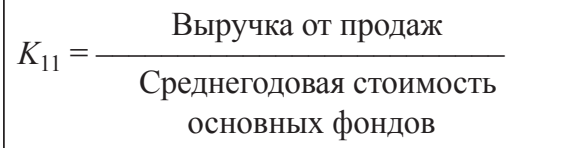 & $\begin{array}{l}\text { Среднее значение } \\
\text { по виду экономической } \\
\text { деятельности }\end{array}$ & $\begin{array}{l}\text { Оценка эффективности } \\
\text { основных фондов }\end{array}$ \\
\hline
\end{tabular}


сово-экономических рисков $\left(K_{1}-K_{11}\right)$ в частные $\left(Z_{1}-Z_{11}\right)$ методом стандартизации. Частные показатели могут принимать значения 1 или 0 на основе сравнения с нормативными или средними значениями по отрасли (виду экономической деятельности). Если значение ключевого показателя $K i$ соответствует рекомендуемому или имеет большее значение, частному коэффициенту $Z_{i}$ присваивается значение 1 , в противном случае -0 .

Следующим этапом анализа финансово-экономических рисков является расчет показателя комплексной оценки $Z$, который служит основанием для определения уровня финансово-экономической устойчивости предприятия (табл. 3). На основании значений частных показателей $Z_{1}-Z_{11}$ рассчитывается показатель комплексной оценки $Z$ :

$Z=0,5\left(Z_{1}+Z_{2}+Z_{3}\right)+0,3\left(Z_{4}+Z_{5}+Z_{6}+Z_{7}+Z_{8}\right)+$ $0,2\left(Z_{9}+Z_{10}+Z_{11}\right)$.

Удельный вес каждой из трех групп частных показателей $(0,5 ; 0,3 ; 0,2)$ установлен с помощью методов оценки тесноты связи каждой группы по их влиянию на комплексный показатель.

На основе проведенного анализа финансовоэкономической устойчивости предприятия можно сделать вывод о целесообразности дальнейшего сопоставления экономических характеристик предприятия и государственного заказа, поскольку организации, попавшие в зоны «Несостоятельность» и «Кризисная зона», не допускаются к следующим этапам оценки.

Далее производится диагностика экономических характеристик размещаемого государственного заказа. На данном этапе должны быть описаны требования, зависящие от технического задания государственного заказа и предъявляемые к производственному потенциалу предприятия для успешного выполнения заказа. К таким требованиям могут относиться:
- объем и номенклатура выпускаемой продукции (работ, услуг);

- длительность выполнения работ;

- численность и структура персонала;

- стоимость и структура основных средств;

- объем инвестиций на выполнение заказа и др.

Для оценки возможности размещения государственного заказа определяется соответствие производственного потенциала предприятия определенным требованиям государственного заказа, а также сравниваются значения показателей комплексной оценки финансово-экономической устойчивости

Уровни финансово-экономической устойчивости

Таблица 3

\begin{tabular}{|l|l|}
\hline \multicolumn{1}{|c|}{$\begin{array}{c}\text { Комплексная } \\
\text { оценка }\end{array}$} & \multicolumn{1}{c|}{$\begin{array}{c}\text { Характеристика финансово-экономиче- } \\
\text { ского состояния }\end{array}$} \\
\hline$[3,6-2,0]$ & Устойчивое финансово-экономическое состояние \\
\hline$(2,0-0,0]$ & $\begin{array}{l}\text { Неустойчивое финансово-экономическое состоя- } \\
\text { ние, в том числе: }\end{array}$ \\
\hline$(1,6-1,1]$ & «Кризисная зона» \\
\hline$(1,1-0,0]$ & «Несостоятельность» \\
\hline
\end{tabular}

предприятия-претендента и условного эталонного предприятия. Сопоставление проводится по каждому виду производственных ресурсов: персоналу, основным средствам, оборотным активам. На основе такого анализа определяются «узкие места» в деятельности предприятия и, соответственно, идентифицируются возможные риски невыполнения государственного заказа по каждому виду производственных ресурсов.

Предложенный метод оценки финансово-экономической устойчивости предприятий - потенциальных исполнителей оборонного заказа может стать основой регулирования отношений между заказчиком и исполнителем государственного заказа, поскольку дает возможность отсеять ненадежных претендентов на стадии выбора исполнителя государственного заказа.

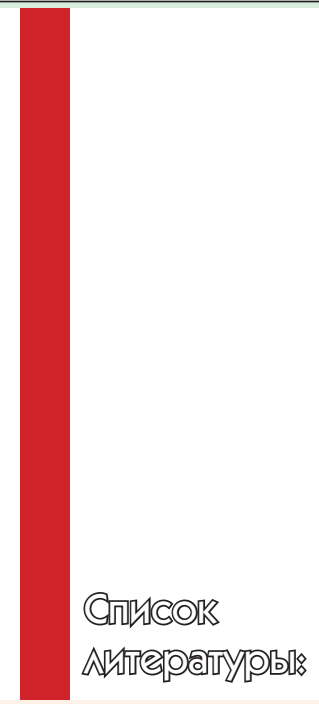

1. Единая информационная система в сфере закупок. ( [Б.г.]). URL: http://www.zakupki.gov.ru.

2. Кандыбко Н. В., Авдеев М. В. (2015) Проблемы выполнения государственного оборонного заказа в экономико-правовых условиях 2015 года // Военная экономика и финансы. № 3 (32). С. 83-89.

3. Лютер Е. В. (2012) Диагностика причин кризиса на предприятии. М.: ИВАКО Аналитик. 99 с.

4. Новый оборонный заказ. URL: http://dfnc.ru/category/oboronzakaz/.

5. Рогозин: коррупция в гособоронзаказе должна быть приравнена к госизмене // Информационное агентство России «ТАСС».

URL: http://tass.ru/politika/1115954.

6. Федеральная служба государственной статистики http://www.gks.ru.Федеральный закон от 05.04.2013 N 44-Ф3 (ред. от 03.07.2016) «О контрактной системе в сфере закупок товаров, работ, услуг для обеспечения государственных и муниципальных нужд» (с изм. и доп., вступ. в силу с 15.07.2016) // КонсультантПлюс. URL: http:/www.consultant. $\mathrm{ru} /$ document/cons_doc_LAW_144624/.

7. Федеральный закон от 29.12.2012 № 275-Ф3 (ред. от 03.07.2016) «О государственном оборонном заказе» // КонсультантПлюс. URL:http://www.consultant.ru/document/cons_doc_LAW_140175/.

8. Чеботарев В.С., Тимченко А. В. (2014) Актуальные проблемы процесса государственных закупок // Вестник Нижегородской академии МВД России. № 2 (26). С. 155-158. 